\title{
Professional Knowledge and Teacher's Reflections in Teaching a Situation Involving the Idea of Proportionality
}

\author{
Angelica da Fontoura Garcia Silva ${ }^{a}$ \\ Sandra Cristina Lopes $\mathbb{1}^{\mathrm{b}}$ \\ Maria Elisa Esteves Lopes Galvão(1) \\ a Universidade Anhanguera de São Paulo (UNIAN), Programa de Pós graduação em Educação Matemática, \\ São Paulo, SP, Brasil \\ b Secretaria de Educação de Barra Mansa, Barra Mansa,RJ, Brasil \\ Received for publication on 6Jan. 2020. Accepted after review on 2 May 2020 \\ Designated editor: Claudia Lisete Oliveira Groenwald
}

\begin{abstract}
Context: Study groups of teachers who meet to reflect on the teaching of mathematics constitute potentially a formative process that can foster teachers' professional knowledge . Objectives: This investigation brings results on the development of professional knowledge of a teacher who delves into ideas related to the concept of proportionality and her teaching during her participation in a study group. Design: The research is of a qualitative nature. Environment and participants: The research was carried out within a study group formed at the school the teacher works, involving seven educators, including teachers and researchers. Data collection and analysis: Data were collected through direct observations, recordings of two study sessions and the development of a class. Observations and reflections on the teaching practice are collected during group studies, based on Zeichner and Ball, Thames and Phelps were analyzed. Results: Their experiences enabled the teacher to expand significantly the knowledge base about the situation presented, and fostered her reflections on the theme and her teaching, especially regarding the resolutions the students presented. Conclusions: The analysis of the process reveals that the proposal to solve problems related to the ideas of proportionality and the analysis of the way students work in the classroom to solve them brings a new meaning to the teacher's knowledge, helping teacher to become more confident to intervene constructively in the students' learning process.

Keywords: study groups; teachers' professional knowledge; reflections on practice; proportionality.
\end{abstract}

Corresponding author: Angélica Fontoura Garcia Silva. Email: angelicafontoura@gmail.com 


\section{Conhecimentos Profissionais e Reflexões de uma Professora ao Ensinar uma Situação Envolvendo a Ideia de Proporcionalidade}

\section{RESUMO}

Contexto: Grupos de estudos de professores que se reúnem para refletir sobre o ensino da matemática se constitui, potencialmente, um processo formativo que pode favorecer o enriquecimento do conhecimento profissional docente. Objetivos: Esta investigação traz resultados sobre o desenvolvimento de conhecimentos profissionais de uma docente que se dedicou ao aprofundamento de ideias relacionadas ao conceito de proporcionalidade e seu ensino durante sua participação em um grupo de estudos. Design: A pesquisa é de natureza qualitativa. Ambiente e participantes: A pesquisa se realizou no interior de um grupo de estudos formado na escola de atuação de uma professora integrante de um grupo de estudos constituído por 7 educadores, entre professores e pesquisadores. Coleta e análise de dados: Os dados foram coletados por meio de observações diretas, gravações de duas sessões de estudos e desenvolvimento de uma aula. Analisaram-se observações e reflexões sobre a prática docente coletadas durante estudos em grupo, fundamentadas em Zeichner e Ball, Thames and Phelps. Resultados: As experiências vivenciadas propiciaram à professora ampliar significativamente a base de conhecimentos acerca da situação apresentada, incentivando suas reflexões sobre o tema e seu ensino, sobretudo a respeito das resoluções apresentadas pelos estudantes. Conclusões: A análise do processo desenvolvido revela que a proposta de resolução de problemas relacionados às ideias de proporcionalidade e a análise da forma de trabalho dos estudantes em sala de aula, para resolvê-los traz um novo significado para o conhecimento do professor, assim como mais confiança para intervir de forma construtiva no processo de aprendizagem dos estudantes.

Palavras-chave: grupos de estudos; conhecimento profissional docente; reflexões sobre a prática; proporcionalidade.

\section{INTRODUCTION}

The relevance of directing the gaze to the teachers' professional knowledge becomes especially evident in the reflections we share with Borba and Silva (2016). The authors state that teachers' knowledge base when teaching presupposes the development of knowledge of different nature and that such teachers' knowledge is a two-way path since they can influence teaching practice, and this practice can influence the development of new knowledge.

In this context, we believe it is essential to focus on the professional knowledge a teacher developed while participating in a study group to further her studies on proportionality in the context of the school where she taught. We chose this study group to investigate - because we consider, agreeing with Nacarato (2000); Fiorentini (2004), Robutti et al. (2016), Correia (2018) and Miranda (2014, 2019), that this type of training can favor mathematics teachers' professional learning.

This study group first met at the invitation of the researchers to discuss issues related to proportionality. Research works such as those by Lesh, Post, and Behr (1988) base the relevance of the topic, highlighting its complexity and relating it to the development of skills that allow us to analyze covariation and comparisons, besides storing and mentally processing various types of information. 
In this context, in this work, we examine the professional knowledge evidenced by a group participant - Teacher A - by exposing episodes in which this teacher solved, prepared, developed her class, and collectively discussed what happened in the teaching practice of a problem involving proportionality idea.

In the study sessions, we analyzed some situations Bryant, Nunes, Evans, and Terlektsi (2012) proposed in the project "Teaching mathematical problem solving in primary school" and, based on their ideas, we discussed with the group the teachers' role as an "intellectual leadership" in their classroom. These authors consider it essential that the teacher thinks about the activities (planning) and how students react to them, and, after that, intervene to help them in mathematical learning. This "thinking about activities and reactions" requires that teachers study, discuss, and reflect. To delimit our research problem, we will present the theoretical framework, the research procedures, the analysis, and the data discussion.

\section{REFLECTING ON THE PRACTICE AND PROFESSIONAL KNOWLEDGE FOR TEACHING: THEORETICAL ASSUMPTIONS}

To proceed with the analysis of the results, we considered the distinct categories of knowledge for teaching established by Ball, Thames, and Phelps (2008), namely: common, specialized or horizon content knowledge, content and students knowledge, content and teaching knowledge, and curriculum knowledge.

According to the authors, common content knowledge allows the teacher to use terms, representations, and notations correctly and to identify inaccuracies or inadequacies in the students' productions and didactic materials. In this study, we will identify the teacher's ability to resolve the situation. Specialized content knowledge, on the other hand, refers only to teaching. It involves the knowledge the professional mobilized to recognize, for example, the different ways of expressing a resolution for a given situation. Such knowledge can help the teachers who are going to teach mathematics to look more closely at how their students are thinking, identifying if it is mathematically correct for a given situation, and if the scheme used would work in general. The horizon content knowledge allows the teacher to interrelate mathematical themes, both within mathematics as a subject matter and in other areas of knowledge, requiring the teacher to master the knowledge that enables connections and articulations of the content taught. The content and student knowledge, on the other hand, relates the understanding of the mathematical content to the knowledge of the students' mathematical thinking, allowing teachers to interpret and predict frequent errors. Content and teaching knowledge is intrinsically linked to the teachers' work. It is based on the understanding of specific mathematics content, combined with the understanding of the pedagogical contexts that enable them to interfere in the teaching and students' learning processes. Finally, curriculum knowledge is the set of curricula recommendations and discouragements on instructional materials that can support teaching practice and those that teachers should avoid. 
The analysis of the collective reflections observed was based on the investigations of Zeichner (1993) and Serrazina (2012). Zeichner (1993) highlights it is important to be attentive to the teachers' practice, since it is "[...] the result of one or the other theory, whether it is recognized or not. Teachers are always theorizing, as they face various pedagogical problems, such as the difference between their expectations and the results" (Zeichner, 1993, p. 21). Throughout the sessions, we tried to provide interactive spaces for study, reflection, and dialogue on the topic, besides offering moments for the collective analysis of situations to be (or that were) developed in the classroom.

Serrazina (2012) helps us to understand the relationship between professional knowledge and reflection on practice. Based on Schön (1983), the author discusses this relationship:

[...] the teachers' professional knowledge, especially their didactic and mathematical knowledge, develops essentially through reflection before the action, during the action and after the action (Schon, 1983) about the concrete and real teaching situations, that allow to analyze and identify the success factors, as well as the origin of the difficulties encountered, taking into account the intentions and objectives with which the educational action was planned. (Serrazina, 2012, p.273)

In this context, during the group studies, we sought to reflect on the situations presented in order to analyze more critically what we planned and how the teaching actually took place.

\section{METHODOLOGICAL PROCEDURES}

This qualitative research requested an ethical evaluation by the CEP/CONEP system and was approved under number 42499115500005493 . It analyzed the participation of a teacher in a study group of 7 educators, including teachers and researchers. This teacher, identified here by A - the first letter of the alphabet - to preserve her identity, has a higher education degree in Pedagogy, and has been teaching the early years for 19 years.

The data were collected during the study sessions through written records of the resolutions of the activities proposed by the researchers and video recordings of these sessions and the class developed by teacher A. To analyze the video data, we used the critical event concept as described by Powell, Francisco, and Maher (2004):

an event is called critical when it shows a significant or contrasting change from a previous understanding, a conceptual leap from a previous conception. Critical events are contextual. An event is critical in its relation to a specific question pursued by the research. Thus, an instance in which learners present a mathematical explanation or argument can be significant for a research question concerned with the students' construction of mathematical rationale or demonstration and, 
thus, can be identified with a critical event. (Powell, Francisco \& Maher, 2004, p. 104-105).

In this context, we tried to follow the authors' guidelines and selected moments in which we observed that the participation of teacher A boosted the reflection on practice in the group. The studies by Powell et al. (2004) also helped us to choose the events that the group would discuss throughout the work. In this article, we will also analyze an event derived from the class developed from the situation presented below, which we consider critical at the moment of the teacher's performance, and we took it for the group to analyze. Figure 1 shows the activity developed in the classroom.

Figure 1

Activity developed in the classroom (Bryant et al., 2012, p. 43)
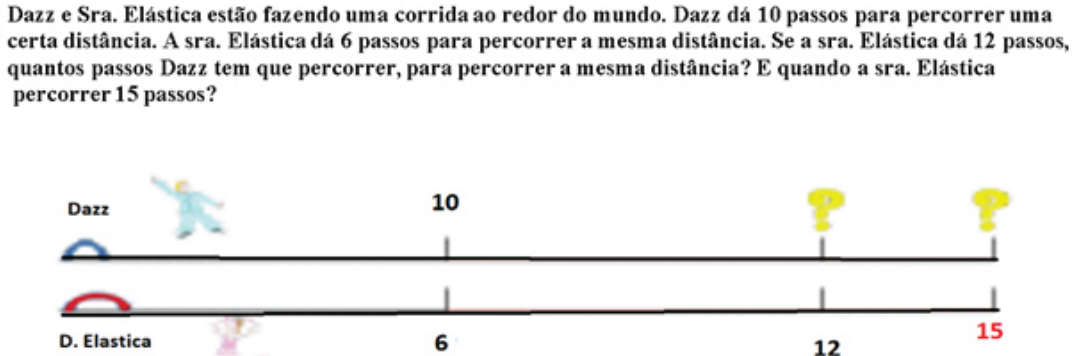

\section{STUDY GROUP: SCENARIO FOR THIS INVESTIGATION}

The group was formed in a municipal school in Greater São Paulo to study and experience situations proposed by Bryant, Nunes, and Evans (2012). Figure 2 shows a diagram with the stages of the work. We started the discussions and reflections by proposing a situation close to what the students would find in the classroom (1). After this stage, aiming to identify and understand the children's strategies and plan the intervention the teachers would perform in the classroom, the group analyzed students' solutions presented in a pilot study (2) that one of the researchers had conducted before the study sessions. This pilot study was carried out with fourth-grade students from another school unit, addressing the same situations the researcher would propose to this study group. This pilot study aimed to generate data for the study group's discussion in stage (2). After having the results of this preliminary analysis, the study group planned the class they would develop with their students (3). Next, the activity was developed in the classroom, with the participation of the researchers and the classroom teacher (4). Finally, the study group resumed their discussions about their classroom experience (5 and 6). Figure 2 outlines the stages that the study group developed. 


\section{Figure 2}

Scheme of the stages that the study group developed (Lopes, 2017, p.124)

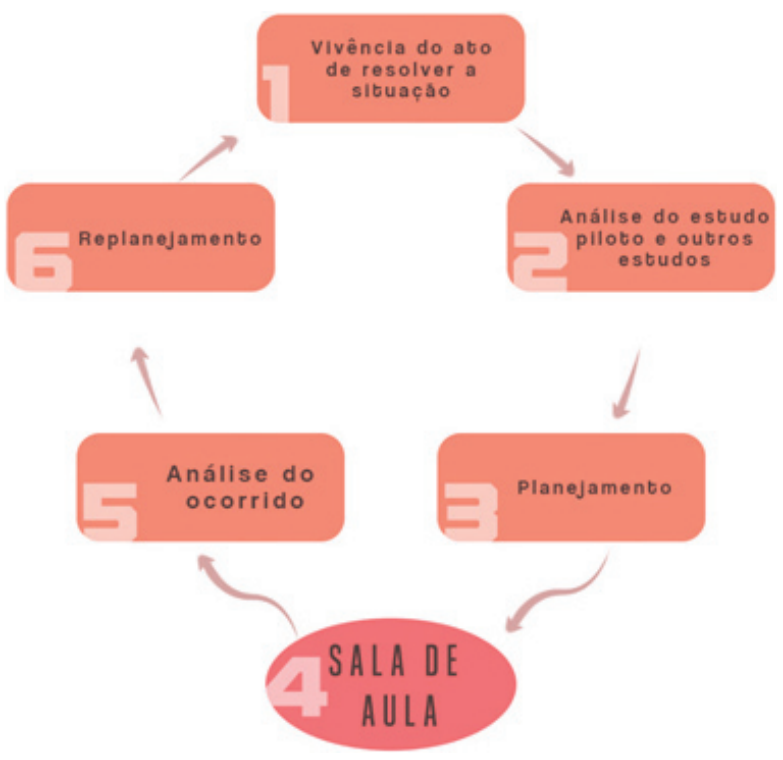

In this article, we present data collected in stages $1,2,3,4$, and $5^{1}$, including those related to the teacher's knowledge and reflections generated within the group investigated - stage 5 - during the development of the class - stage 4.

\section{RESULTS AND ANALYSIS}

We will analyze the five stages related to the proposition of the situation that involved the idea of proportionality. The data resulted from the group's studies carried out - the experience, analysis, selection, and planning of the situations that would be developed with the students.

\section{Stages 1 and 2: group's experience and analysis of the situation}

The group started work by analyzing the situation shown in Figure 1 (p. 5). The participants' first reaction was to recognize that the situation could be resolved using the idea of multiples. It is possible to notice that the teachers initially seem to find it challenging to deal with the diagram presented next to the statement of the situation. However,

\footnotetext{
${ }^{1}$ We chose to suppress stage 6 because of the limited space to present the whole investigation. Also, during re-planning, the group decided to present the students with another situation and, in this way, the study group focused on it.
} 
throughout the discussions, they tried to justify their answers from the mathematics perspective. Figures 3, 4, and 5 and the respective dialogues illustrate the teachers' reasoning. Figure 3 shows the image of the Teacher (B) when solving the problem.

Figure 3

Teacher (B) solves the problem (Lopes, 2017)

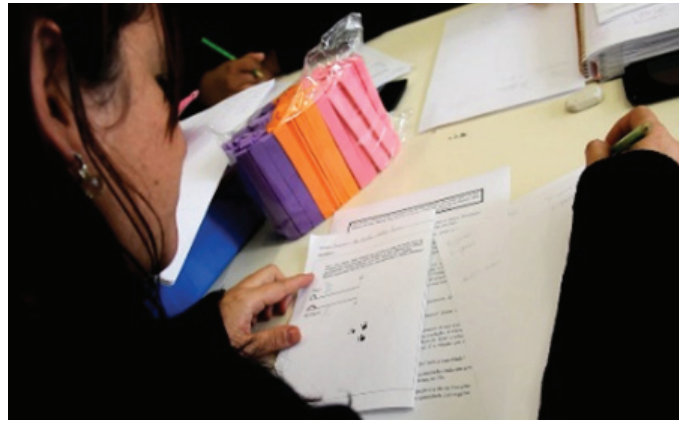

Teacher (A) - This looks like problems of multiples.

Teacher (D) - I was paying attention only to the numbers and had not looked at the figure... In my mind, only the numbers were enough. And there are also the little arrows... that help... I thought of the difference first. I thought that one takes 10 steps and the other 6 , so the difference is 4 . Am I getting it right?

Teacher (A) - I am going by the same logic.

Teacher (B) - At first I was thinking like you, but when I looked at the picture... I'm thinking differently now. I thought of one thing and now another, because of the image.

Teacher (A) - I think that with the multiples, it wouldn't work very well, no! That's why I stopped! Elástica took 10 steps, and the other, only 6. If it is 12, that is double, then it is 20.

Teacher (B) - I got two results. I got to the double, that is 20 , and I also got to 8 , because of the difference, then it doubles, and 4 becomes 8.

Overall, we noticed that Teacher (A) seemed a little unsure about the best strategy. It was clear that this common knowledge of the content was not part of her repertoire as she moved between additive and multiplicative reasoning, and she did not seem to realize that she could use the multiples to solve the situation. However, in the end, she seemed to find the solution to the situation by using the idea of doubling.

Observing what happened, the researchers sought to expand the mathematical discussion on the idea of multiples, reflecting with the group on the relationship of this mathematical content with the idea of proportionality. After that, we tried to deepen the analysis of the strategies previously discussed on the number of steps, but the teachers did not pay attention to the increase in the same proportion of the difference between the steps the two characters took. In this context, the researchers called the group's attention to that fact. We observed that the teachers seemed to recognize the proportional increase. Figure 4 shows the scheme Teacher (D) used. 
Figure 4

Scheme used by Teacher (D) (Lopes, 2017)

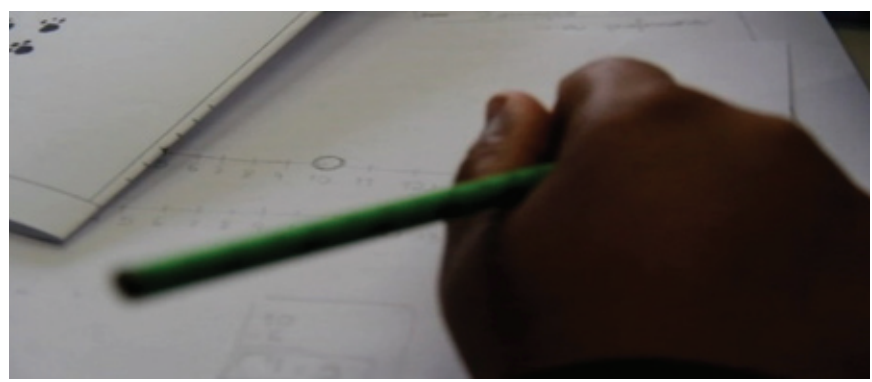

Researcher (1) - Let's try to understand what you are talking about... One thing was what you did... six steps... so, as Elástica walked twice as much, plus six, for her to take 12 steps. And Dazz? At first she was at 10 and, after walking, where will Dazz be?

Teachers - 10, also.

Researcher (1) - So..

Teachers - 10 and 10 , will be in 20 .

Researcher (1) - This is a way of thinking proportionally, don't you think? What is the difference in thinking for those who answered 8?

No one answered immediately. The group reflected on the situation.

Teacher (A) - See, she looked at the difference between the distances, but the question was not about the difference, is that so?

Teacher (B) - Wow, it's true, look at the difference, it was 4 steps between Elástica and Dazz, then we took 4 out of 12 , so it was 8 .

Teacher (D) - I should have continued my graph [referring to the representation on the line see Figure 4], which I was doing number by number. Then in the middle, I thought l'd find the difference first, but can't you make it by the difference?

Researcher (1): Let's think: here we were analyzing what happened to Elástica's steps, and when I analyzed Dazz's separately, I kept the same "proportion" between their steps.

Teacher (A) - Elástica doubled, and Dazz also doubled.

Researcher (1): Yes. But in a proportional relationship, do you think the difference remains? What do I have to see?

Teachers - Silence.

Researcher (2): Let's think about another example: if I use 2 cups of sugar for 3 of milk, if I double the recipe, it will be...?

Teachers - 4 of sugar to 6 of milk.

Teacher (B) - Wow, it's true, the difference between sugar and milk at the beginning was 1 and changed to 2, the difference is not kept.

Teacher (A) - It is true, the difference doubles, too.

Teacher (D) - So, I was on my way, I just needed to take the difference that was 4 and double, 8 and add to 12, I would give 20.

Teacher (B): It's funny, you get anxious, you want to get it right, and you're unsure. Thinking that you need to finish it quickly, and we don't even think that this is no longer a problem of comparing relationships [referring to the previous situations]. 
In this episode, it was possible to highlight Teacher (A)'s concern with explaining her reflection on her colleagues' way of thinking "See, she looked at the difference between distances, but the question was not about the difference, is that so?"; she was the one who drew the group's attention to look at the difference and concluded that the difference also doubled. In this context, we consider that Teacher (A), like the others, at first found it difficult to observe the proportionality presented in the situation. However, at this post-action point in the group discussion, she seemed to look at the situation in a more investigative way, as Serrazina (2012, p.273) points out. We believe that she was already showing some concern in investigating "the origin of the difficulties the group encountered" to resolve the situation.

After this discussion, we tried to reflect on the differences and similarities between additive and multiplicative reasoning, besides showing the difference between the situation of comparison that involved proportionality. At the end of the discussion, Teacher (B) recognized the difference between the situations that involved the "comparison of relationships" and the situation under study; however, as Teacher (A) did not say anything, we had no evidence whether she had recognized it.

Through analyzing what happened - besides statements such as those of Teacher (A), who repeatedly highlighted: "we need this a lot, to study the content more to understand better how teaching takes place" - the group's participants could verify they needed to deepen their mathematical content and teaching knowledge, that is, to master knowledge that combines teaching knowledge and mathematics knowledge (Ball et al., 2008).

It is essential to mention that the situation's proportional reasoning was not trivial, since, after the study group resumed the session, the group was asked another question about the same problem. At the time, it became clear that Teacher (B) still found it complex to explore the properties related to the proportionality factor. Figure 5 shows Teacher (B) explaining her reasoning to the group. 


\section{Figure 5}

Teacher (B) explaining her reasoning (Lopes, 2017)

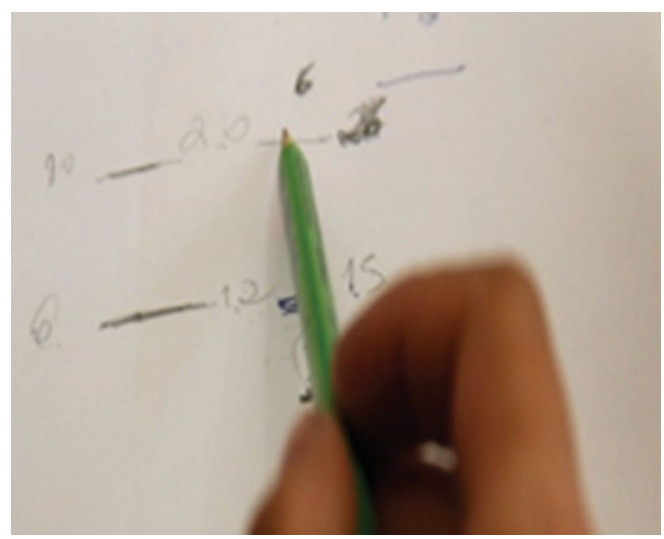

\footnotetext{
Researcher (2) - Teresinha takes" another question to the students: "Ask the students to find out how many steps Dazz takes when Mrs. Elástica takes 15 steps ".

Researcher (1) - Let's think. Elástica walks 6, then 6 more, totaling 12.

Teacher (B) - I found 26.

Teacher (A) - Why 26?

Teacher (B) - Because it was 3 more, and, as it is always doubling, then it will be 6 more. From 6, it doubled, to 12. From 10, it doubled to 20. If it increased by 3 here, then the other will double, then 6.

Teacher (B) - So I can't put 3 on top because it takes more steps, so I have to double on top, because it takes longer, that's why I found 6 . It is twice the 3 .

Researcher (1) - It will increase, but is it two times the steps Elástica walked? [at that moment, Teacher (B) got lost in her thoughts and was interrupted by Teacher (D)]

Teacher (D) - I think that if I am looking at Dazz and Elástica, I have to look separately, I only double the difference that would be 16, but if I wanted the double, but it is not double.

Teacher (A) - I arrived at 25. From 0 to 6, from 6 to 12 and from 12 to 18, if she took 6 more... and the other would reach 30 , increasing by 10 s. To get to 15 , it would be half of 12 to $18 \ldots$ half of 6 would be $3 . .$. the top half (range between 20 and 30) was 25.

Teacher (B) - Now I understand, I have to look at Dazz. It's 25.
}

The group analyzed that this situation emphasized the idea of correspondence, exploring the relationship of proportionality for each character; however, we noted that the doubts Teacher (B) had could be linked to the relationships established with the addictive situations resolved by the group in other study sessions. This time, Teacher (A) was more confident when she presented her resolution - common content knowledge - however, she still did not seem to be so confident about interpreting her colleague's mistake - content and student knowledge - (Ball et al., 2008). 


\section{Stage 2 and 3 - Analysis of the children's strategies in the pilot study ${ }^{2}$ and the lesson planning to be developed}

The group also analyzed three protocols of the students of the pilot project because we believe that it is important, agreeing with Ball et al. (2008, p.7), that the teacher reflects on the students' possible strategies (whether correct or not) and identifies the source of the mistakes the students made (a skill that is part of the specialized content knowledge). To illustrate, we expose the discussions generated from the analysis of Student C's response. Figure 6 shows the protocol of Student C of the pilot study in relation to Dazz's and Mrs. Elástica's problem.

Figure 6

Protocol of Student C of the Pilot Study in relation to Dazz's and Mrs. Elástica's problem (Lopes, 2017)

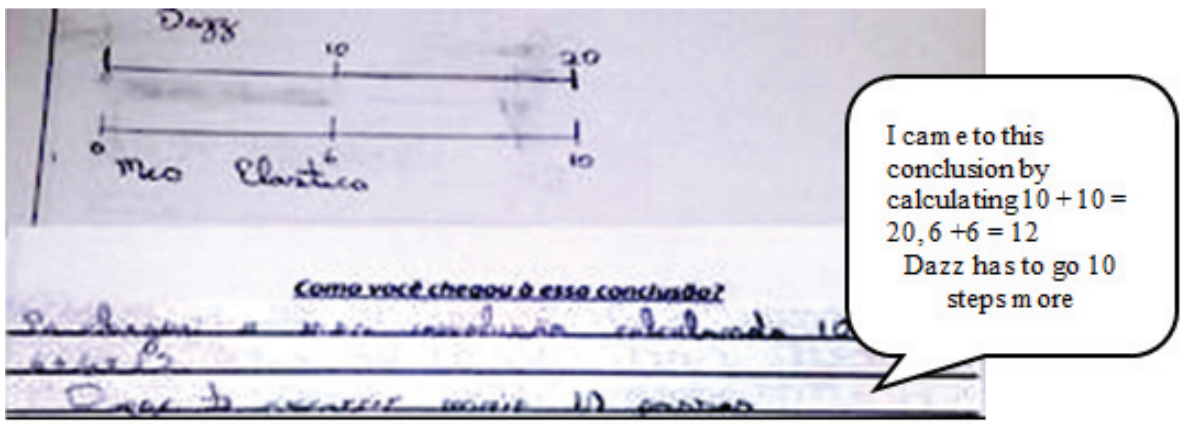

Teacher (B) - The answer was 10, but 10 is the difference, isn't it? It is wrong.

Teacher (A) - What the student thought here. He did it right, $10+10=20$ and $6+6=12$. [pointing to the answer described by the student in the item "how you reached the conclusion"]. It seems that he made a mistake while writing on the graph, instead of 12, he registered 10. The reasoning was correct: Dazz was already at 10, and will go another 10 steps.

Teacher (B) - The teacher can interpret it as if he had made a mistake because he wrote that "Dazz took 10 steps more" [referring to the answer recorded by the student], but the student thought carefully: instead of registering from the beginning, he indicated from 10 steps Dazz had already taken.

Other protocols were analyzed, but the teachers' most significant concern was to discuss whether the students would be able to solve the situation using the bars ${ }^{3}$ or if the best option would be, as suggested by Bryant et al. (2012), let them solve it supported by the scheme presented for the situation. Teacher (A) stated that the bars were not used. Figure 7 shows the resolution of the first question of the problem with the use of bars, and Figure 8 shows the resolution of the second question.

\footnotetext{
${ }^{2}$ We reiterate that in a pilot study with a group of Brazilian students, we developed the sequence proposed by Nunes et al. (2012) aiming, after having experienced possible difficulties encountered by these students, to select situations to develop stage 2. In this research, we showed how the group of teachers analyzed the children's resolution to one of the problem situations.

${ }^{3}$ Supported by Bryant et al. (2012), the teachers proposed, for another situation, problems that had been given previously (not presented in this article), where the students used bars to think about the relationships between quantities; however, for this situation, Bryant et al. (2012) propose only the use of the graphic scheme presented.
} 


\section{Figure 7}

Resolution of the first Dazz's and Mrs. Elástica's problem with the use of bars (Lopes, 2017)

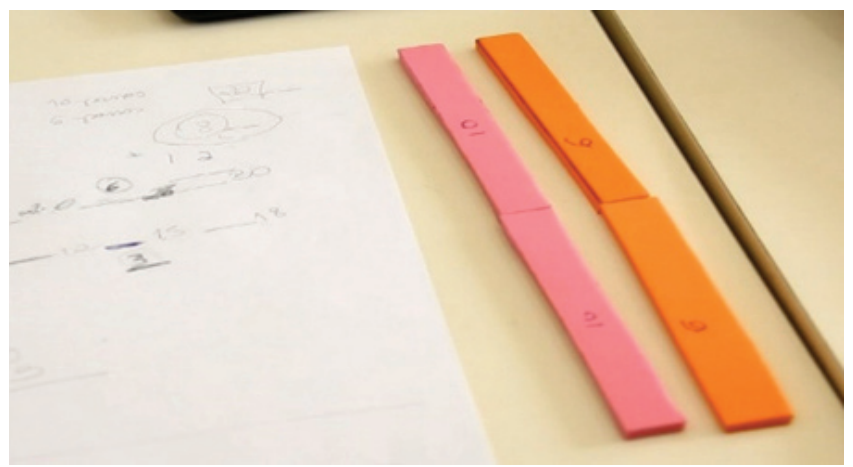

Teacher (A) - I don't know if I would need the bars, because I went straight to the drawing... the double is 20 , but if the child thinks through the bar, will it also work?

Teacher (C) - To establish the relationship by the bar. We can consider that each one-colored bar will be worth 10 steps and for another color, each bar will be worth 6 steps. Then they go, by color, adding another bar equivalent to 6 and the other equivalent to 10. So, it will be 20 [referring to the quantity observed in two pink bars - Figure 7] for one, and 12 for the, other referring to the quantity observed in two pink bars - Figure 7].

\section{Figure 8}

Resolution of the second question of Dazz's and Mrs. Elástica's problem using the bars (Lopes, 2017)

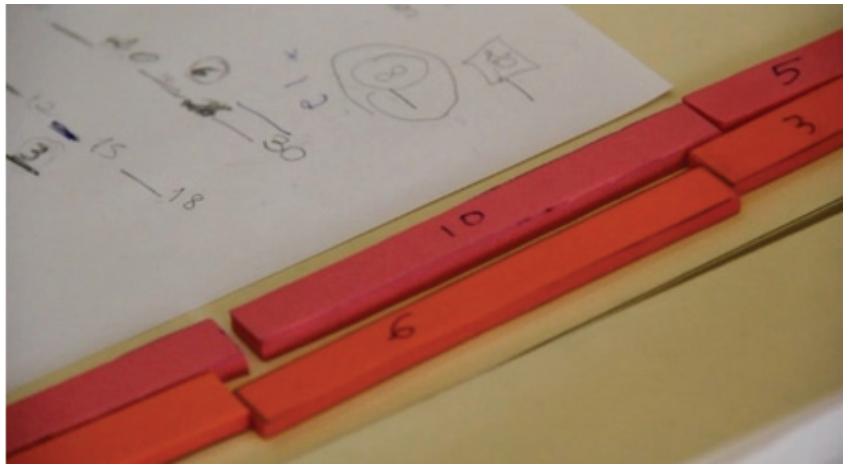

Teacher (B) - It could mix up the space covered and the number of steps.

Researcher (1) - This type of situation is more complicated because it has two variables... the number of steps and the space covered. Until then, they were just looking at the bar and thinking about quantity or the relationship [Mentioning the other situations discussed before this one].

Teacher (D) - So, now when I look at the color, and you say it's the distance, regardless of whether the distance is the same as the first part, my figure will be the same.

Researcher (1) - The distances for the same characters need to be the same, I don't know how much it is, I just know it's the same. One color takes 6 steps, 6 more, it is 12. The other [color] takes 10 steps and 10 more equals 20.

Teacher (D) - We could give them some bars and let them explore and think about a solution, see what is best for them: they decide whether to use them. 
In this session, we noticed that the teachers' concern was on how teaching would be done and not only on the analysis of the schemes students used - more significant focus on content and teaching knowledge (Ball et al., 2008). It is noteworthy that the group's decision to use the bars as support material differs from what Bryant et al. (2012) propose. In this sense, we considered, following Zeichner (1993), that the group's participants assumed a reflexive attitude concerning their teaching, bringing up their "practical theories" for critical analysis and discussion, in this case, the belief that the previous work with the bars could boost student learning. After analyzing the procedures taken to the situation in class, the group discussed the relevance of working with proportionality in the early years, and teacher (A) again considered:

Teacher (A) - For example, since recipes, fraction, percentage, you work a lot with proportionality and use proportional reasoning, which is something we don't care about [mentioning the fact that often teachers do not recognize that they are dealing with this issue]. And the current curriculum has drawn attention to those things. And often the problems we choose to work on in the room do not favor this. It is the proportionality that he will use on a daily basis. This is what the student will use. Encourage thinking.

Teacher (D) - And now it is clear to us, when you are there dealing with the student, it is so much easier to intervene. After we go through this process and understand the relationship, it is much easier to explain it to them.

At this moment, Teacher (A) sought to interrelate the issue of proportionality with mathematics as subject matter and with reality. At the end of the session, they planned the class: they chose to present the situation as it was developed in the group, offering children colorful bars that could be used to represent the steps of each of the characters in the problem ${ }^{4}$. Based on Ball et al. (2008), we consider that the mastery of the horizon content knowledge on proportionality expanded the possibilities for Teacher (A) and the other members of the group to establish connections between the various mathematical contents. Such mastery can also favor the development of curriculum knowledge regarding proportional reasoning.

It is possible to affirm that the resolution of this type of situation only became evident for the participants of this study after they discussed the situation further. It was possible to identify, from Ball et al. (2008) that, as the teachers' mastery of specific content - in this case, of proportional reasoning - increased, there was an equal expansion of knowledge for their teaching, for example, when Teacher (A) stated: "we don't work much with that idea in the classroom."

Through the participants' statements, we can see the evidence of one of the characteristics that basic teacher training pursue: the collective subject. We observed that the participants seemed to understand collaboration as an effective way to face the

\footnotetext{
${ }^{4}$ In group studies we analyzed the Singapore Model Method (MMC, in Portuguese acronym), and we proposed that children used bars to model the situations. The SMM is a specific method for solving mathematical problems that uses rectangular bars as pictorial representations of quantitative relations in problem situations.
} 
problems and challenges of teaching practice, in the context of uncertainties and changes (Fiorentini \& Nacarato, 2005).

\section{Stage 4 - Immersed in teaching practice}

In this stage, we present the work in Teacher (A)'s classroom, using the same situation. Initially, the teacher handed the sheet with the questions and read the activity aloud to the class, while the students followed closely. Then she asked the students to observe the drawings and record everything carefully. Teacher (A) guided them: "Then you will have to think a lot! Read it again. Look at the drawing! Look at the question there. I want to know how many steps Dazz will take when she [mentioning Mrs. Elástica] takes 12 steps".

The teacher was concerned with guiding students to observe punctuation, graphical representation, and questioning. She reported that the first question was solved without further problems. She asked the students about the resolution and, when she realized that most had already finished solving the first question correctly, she went to the front of the room to read the second question aloud, asking them again to observe the drawing: "Mind that one! You have to think a little! Look at the drawing and think!'”. As we had solved the question in the study group and there were many discussions around this activity, the teacher's first idea, possibly, was that the students found it as challenging as the teachers' group had. Thus, she went to the desks to investigate the children's strategies, exemplified here in Figures 9 and 10. Figure 9 depicts Student 3 presenting the solution he thought for the second question of the situation.

\section{Figure 9}

Student 3 showing the solution to the second question about Dazz and Mrs. Elástica (Lopes, 2017)

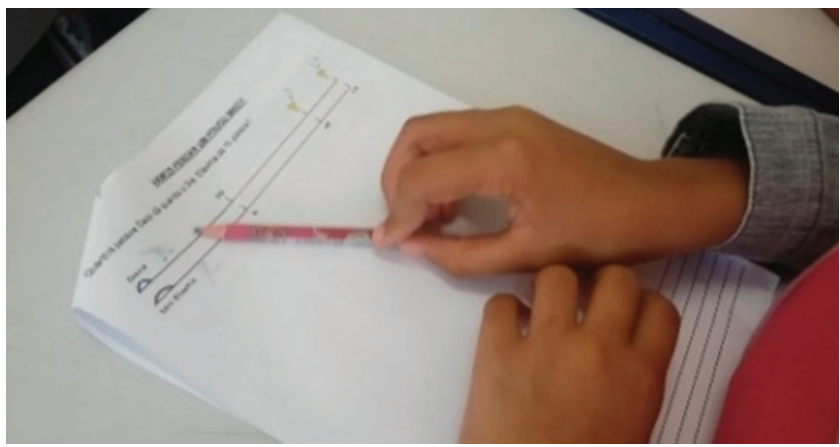

Student 3 - Dazz took 10 steps. And 10 plus 10 is 20. Mrs. Elástica took 6 with 6, which is 12. Teacher (A) - But why 25? How did you manage to find the steps for this short piece here? [pointing at the last distance].

Student 3 - However, in the last piece, she divided and gave 15, and half of 6 is 3. So, with Dazz, we did the same. We took 10 and decided it, and the result was 25 . 
The student reasoned proportionately to the steps of each of the characters in the situation. In the same way, teacher A followed other pairs, questioning the reasoning used to arrive at 25, until she was faced with Student 10's doubts. After a few attempts, the teacher called her and decided to use the body to exemplify the relationship between the number of steps Dazz and Elástica had taken. Figure 10 shows teacher (A) proposing to the student experience of what was described in the situation.

\section{Figure 10}

Teacher (A) proposing to the student to experience what was described in Dazz and Mrs. Elástica's problem (Lopes, 2017)
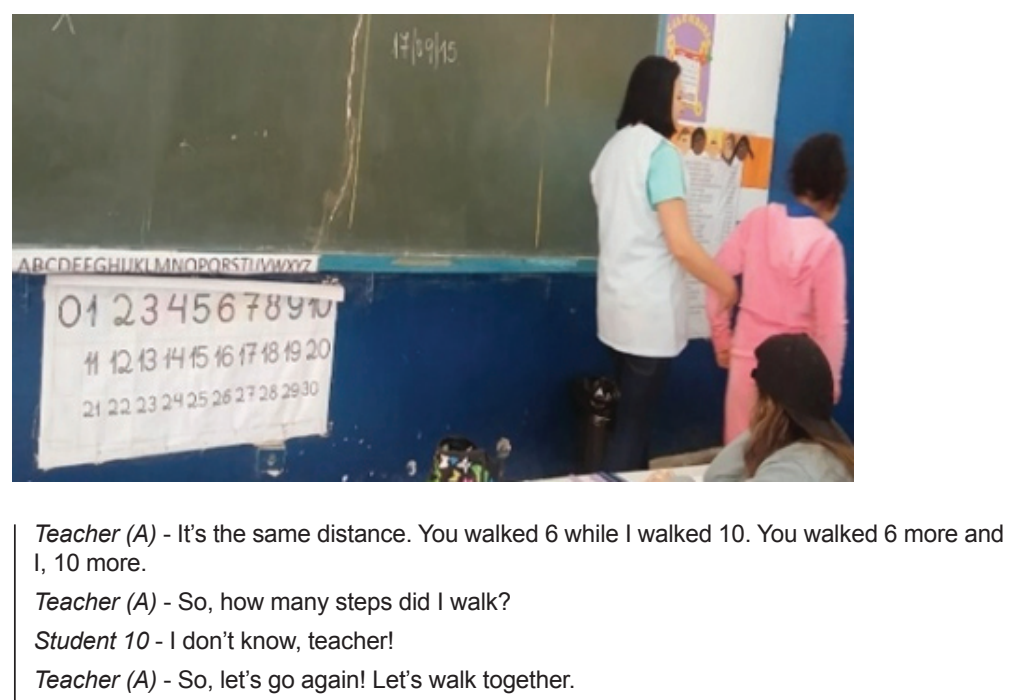

The teacher felt confident to use a strategy not discussed within the group - to actualize the situation. However, we noticed that, when discussing with one of the students, instead of emphasizing the counting of the number of steps, she emphasized the displacement rate. As this did not jeopardize the discussions with the students, the observers did not interfere in loco, postponing the observations for discussion in the teachers' group.

At the end of the class, the teacher called two pairs of students to present the two correct solutions. Students 14 and 15 went to the board to solve the first question. Figure 11 shows the resolution of the situation proposed by a pair of students on the board. 


\section{Figure 11}

Resolution of the situation on the blackboard (Lopes, 2017)

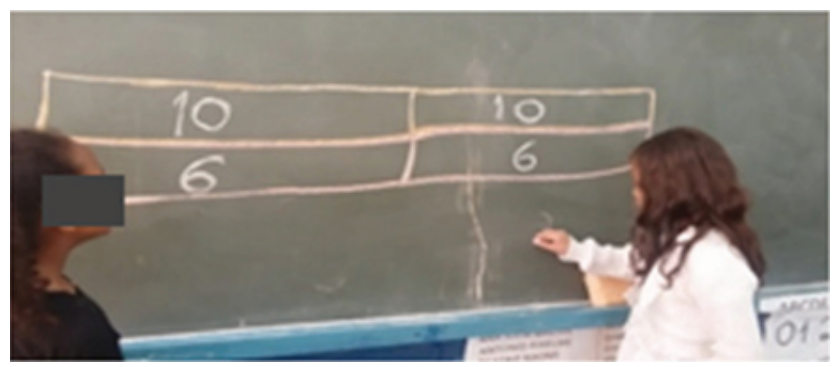

Teacher (A) - Explain how you thought to do this.

Student 14 - We got the pink bar for Mrs. Elástica and the purple bar for Dazz. So, two pink bars are also two purple bars. So it's twice the number of steps.

The students used the bars to answer the question. To refer to the second question, another student - student 21 - went to the blackboard, reproduced the drawing in the situation.

Student 21 - Well, I thought a lot. I looked at Elástica and saw that she had already taken 12 steps and reached 15. She walked 3 steps more. Dazz had taken 20 steps and walked 5 more and took 25 steps.

Teacher (A) - How did you find 5 ?

Student 21 - I saw that Elástica's 3 was half of 6, which was the number of steps she took in each part. Then I thought that the top one was also the same. Half of the steps that Dazz took in each part, so I put 5.

Teacher (A) - Half of 10 ?

Teacher (A) - Did you use the bars?

Student 21 - No, I didn't.

We noticed that when choosing students to present the solutions to their classmates, the teacher tried to pick one student who had solved it with the bar and another one who had not used the resource. However, when socializing the results, she chose not to discuss any of the wrong strategies.

In this class, the teacher showed to have developed an open attitude to dialogue, trying to listen to her students and socializing the results. Overall, we could observe that, on the one hand, the studies carried out within the group developed a knowledge base that favored the teacher to show a more purposeful attitude towards teaching. On the other hand, these studies could not avoid that limitations of common and specialized knowledge jeopardized both the pedagogical knowledge and the teaching and student knowledge (Ball et al., 2008) equally. 


\section{Stage 5: Discussions and reflections on what happened in the room}

The discussions and reflections on the actions developed in the room took place over two days. On the observation day, we analyzed the students' performance and strategies; we categorized the resolutions of Professor (A)'s students into successes and errors: 25 students worked in 11 pairs and a group of 3 . The 25 students got the right answer to the first question of the problem. However, concerning the second question, the result was different. Of the 25 students who solved the second question, 14 answered correctly, and 11 failed to achieve the correct answer.

With those data in mind, we chose to let the teacher report to the other participants how the activity was carried out, and then look more closely at the students' productions, to understand the answer given. Teacher (A) reported that the children quickly solved the situation. At that moment, Professor (B) said: "Was it the one that we couldn't see, Dazz's 5? Did they also have difficulties?" Figure 12 shows the resolution.

\section{Figure 12}

Student 4's protocol regarding the resolution of Dazz and Mrs. Elástica 's second question (Lopes, 2017)

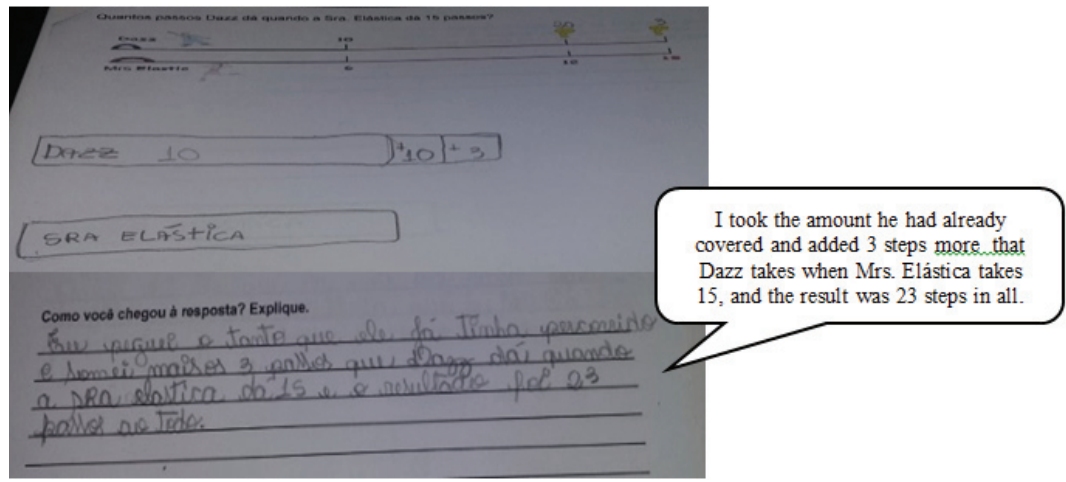

Teacher (A) - That is the thing: no! Some children answered just by looking.

Teacher (B) - I remember that we managed to observe half of Elástica's, but I did not do the same with Dazz.

Teacher (A) - I had to act to try to explain...

Researcher (1) - What difficulties?

Teacher (A) - It was time to think about finishing half the steps. Many of them realized in Elástica drawing that each part was worth 6 and that the final "little part" was worth 3. But they put 3 on top too, so they found 23.

Teacher (A) - Even though I explained it to student 10, showing that it was the same amount, she did not understand.

Researcher (3) - See in the protocol that some students found 3 for Elástica and doubled for Dazz, obtaining 26 as an answer.

Teacher (A) - I noticed several different things. One of them said that each step that Dazz took has a difference of 4 for Mrs. Elástica. He realized that in the second part there was also a difference of 4, and they concluded that in the third part of the steps the difference should also be 4 . As in the range 12 to 15 the difference was 3, they concluded that Dazz's range would have to be $7(3+4)$. Dazz's total steps were 27. Look and intervene, and that is not an easy task. Intervene so that they can see what is really happening, but I noticed that they expanded their justifications [mentioning that students are detailing their resolution strategies better when compared to the beginning of the project]. 
In this dialogue, there is evidence of some of the categories of professional knowledge the teachers explained, especially the specialized content knowledge or content and student knowledge. In this session, the teachers, very concerned with analyzing the children's strategies, considered that, unlike Bryant et al. (2012, p. 46), the students investigated did not find it so easy to think "to halve the number of steps", because, as Teacher (A) justified, "the children were not used to solving this type of problem [linked to situations involving the idea of proportionality]". However, teacher (A) seemed to notice advances in the students' performance regarding the argumentation not only when solving the situations, but also when describing their strategies. On the other hand, it is important to highlight that the participants still had difficulties to problematize the solutions the children found (the connection between content knowledge and teaching and student knowledge). On this theme, the researcher asked the teacher what criterion she used to choose the students who would present their answers to the classroom. Teacher (A) asserts: "In class, I chose to present an answer with a bar and one without it, I chose two students who got it right and I didn't have time to present the other solutions, I wanted to discuss the error, but I didn't feel confident, I thought I could talk nonsense." In this context, we believe that there is more evidence that the teacher, at that moment, still did not feel sure about her content and student knowledge as described by Ball et al. (2008).

In another session, we analyzed the critical event (Powell, Francisco \& Meher, 2004) that we selected to bring to the group for discussion. At first, we asked if they remembered the situation that discussed the steps of Dazz and Mrs. Elástica, and we set out to analyze some sections. We started with excerpts in which Teacher (A) made good questionings, until she presented the scene where she tried to actualize the situation of Dazz's and Mrs. Elástica's steps. Before starting, Researcher (1) emphasized that the intervention had not been perfect due to a detail that could have caused one of the students to find it hard to understand. Figure 13 shows Teacher (A) watching her own intervention when carrying out Dazz and Mrs. Elástica's problem. 


\section{Figure 13}

Teacher (A) watching her own intervention when carrying out of the problem of Dazz and Mrs. Elástica's problem (Lopes, 2017)

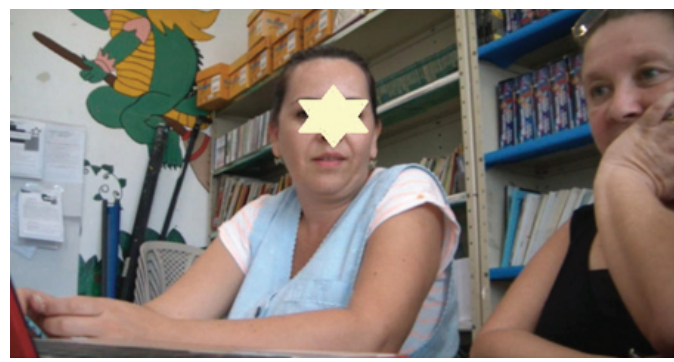

Teacher (A) - What did I do? I didn't see it. She walked 6 and I walked 10, until then it was right.

Researcher (1) - All right.

Teacher (A) - Was it on the way back that I tried to explain it again?

Researcher (1) - No! When you took the step....

Teacher (A) - Was my step almost the size of hers?

Researcher (1) - Let's watch the beginning again.

Once again, we saw the beginning of the video, when Teacher (A) spoke about giving slow and fast steps. She spoke immediately.

Teacher (A) - Slow steps!

Researcher (1) - Was it slow? Or was it short?

Teacher (A) - No! It was short. Oh, Jesus!

Teacher (A) - I understand what went wrong.

Researcher (1) - This would be another variable, it would be the velocity. What we thought was if the student was not confused by that. She may have got confused, don't you think?

Teacher (A) - The slow was very strong for me. And it was short. This is cool. Here we see what we've done and reflect.

Researcher (1) - This is our intention.

Teacher (A) - Sometimes, a word can jeopardize the explanation. Some student also commented that I was supposed to walk slowly, just like his grandfather.

Researcher (1) - Then, it would be another problem. Speaking about a fixed space and a higher or lower rate. If we look into our classroom all the time,

we will always find something we could do differently.

Teacher (A) - Always!

Researcher (2) - Sometimes I leave a class and when I go to the other class to speak about the same subject, I see that I was not happy with some statements and I change it. That is normal!

Researcher (1) - Here we are reflecting on the teacher's action. And the teacher doesn't have time. What we want to put in our work is this importance of having some room for the teacher to reflect. This way they improve their practice. Without shame, without fear.

We all get things right and get things wrong.

Teacher (A) - It was good for me to watch it. Now I have to watch myself more.

Researcher (1) - Just look at the step size. One with a bigger step

and another one with a smaller step 
As Teacher (A) seemed to be uncomfortable with the "mistake", we watched the excerpt from the introductory video in which she explained the problem aloud to the class. We found that the teacher had spoken only of length and steps. To make herself understood to the student, Teacher (A) used staging, and along with it, the "slow" and "fast" steps, instead of long and short ones.

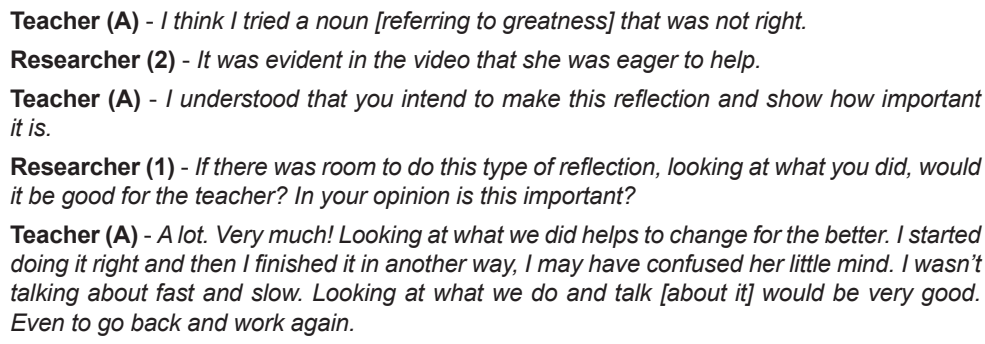

Teacher (A) - A lot. Very much! Looking at what we did helps to change for the better. I started doing it right and then I finished it in another way, I may have confused her little mind. I wasn't talking about fast and slow. Looking at what we do and talk [about it] would be very good. Even to go back and work again.

We noticed that in this episode, Teacher (A), especially, carries out a growing process of reflection on her own practice within the scope of the community of practice constituted for the development of this study. It is possible to notice, considering Zeichner's assumptions (1993), that this session possibly favored what he highlights as professional development. For this author:

One way to think about reflective practice is to view it as coming to the surface of the teacher's practice theories for critical analysis and discussion. Exposing and examining their practice theories, for themselves and their colleagues, the teachers have a better chance of realizing their flaws. Discussing publicly within groups of teachers, they are more likely to learn from each other and have one more word to say about the development of their profession (Zeichner, 1993, p.22)

By exposing and examining Teacher (A)'s theories and practice, we noticed that she did not exempt herself from discussing her difficulties in the community and tried to learn (and teach) her peers about the profession of educating.

\section{CONCLUSIONS}

Throughout the development of group studies, we realized, from the perspective of the mastery of the knowledge proposed by Ball et al. (2008), that the participants expanded their knowledge regarding the situation presented here. The interrelationship between the different categories of professional knowledge raised discussions on proportionality and the teaching of proportionality. The acquisition of common content knowledge was linked to both the questions and the evaluation of practice itself. Teacher (A) improved 
her knowledge regarding the reasoning on proportionality, which favored the expansion of professional knowledge, especially that related to common, teaching, and curriculum knowledge. She developed content and teaching knowledge, but she considers that she still did not feel confident to discuss her students' wrong strategies, that is, she still lacked specialized content knowledge. However, our analysis of the whole process revealed that experiencing problem-solving involving the idea of proportionality and analyzing the way students thought at the time of the resolution, brought a new meaning to teaching knowledge, as teachers felt more confident to intervene more constructively in the students' learning process.

It was possible to verify that Teacher (A), while studying the situation that involved the idea of proportionality within the group, developed what Zeichner (1993) considers a process that involves intuition, emotion, and passion, which expanded her capacity for reflection. Although there were some specific limitations here, we consider that participation in the group allowed Teacher (A) to deepen her way of looking at her practice and her students' learning. In this context, we agree with Serrazina (2012) in that the discussions carried out within this study group contributed significantly to the professional knowledge development of the teachers involved, and allowed a more critical look into their professional practice.

\section{AUTHORS' CONTRIBUTIONS STATEMENTS}

Garcia Silva supervised the project. Lopes and Garcia Silva conceived the idea presented. Lopes and Garcia Silva developed the theory, adapted the methodology to this context, created models, performed the activities, and collected the data within the study group. Lopes and Garcia Silva analyzed the data. Lopes, Garcia Silva, and Galvão discussed the results and contributed to the final version of the manuscript.

\section{DATA AVAILABILITY STATEMENT}

The data supporting the results of this study will be made available by the corresponding author, S.C.L., upon reasonable request.

\section{REFERENCES}

Ball, D. L., Thames, M. H., \& Phelps, G. (2008). Content knowledge for teaching: what makes it special? Journal of Teacher Education, 59(5), 389-407

Borba, R.E.S.R. \& Silva, J.A. (2016) Dize-me o que conheces, e eu te direi o que e como podes ensinar. In: Martins, E. \& Lautert,S. Diálogos sobre o Ensino, Aprendizagem e a Formação de professores: Contribuições da Psicologia da Educação Matemática (pp. 74-97). Autografia. 
Bryant, P.; Nunes, T.; Evans, D.; Gottardis, L.\& Terlektsi, M. (2012) Teaching mathematical problem solving in primary school. Department of Education, University of Oxford.

Correia. D. S. (2018) O desenvolvimento profissional de professores que ensinam as estruturas multiplicativas. (199 f.) Tese Doutorado, Educação Matemática, Universidade Anhanguera de São Paulo, São Paulo.

Dante, L. R. (1998) Didática da resolução de problemas de matemática. 2. ed. Ática. Fiorentini, D. (2004) Pesquisar práticas colaborativas ou pesquisar colaborativamente? In: Borba, M. C. \& Araujo, J. L. Pesquisa qualitativa em educação matemática. (pp.4776). Autêntica.

Nacarato, A. (2000) Educação continuada sob a perspectiva da pesquisa-ação: currículo em ação de um grupo de professoras ao aprender ensinando geometria. (344 f.) [Tese Doutorado em Educação]. Faculdade de Educação, Universidade Estadual de Campinas, Campinas. http://repositorio.unicamp.br/jspui/handle/REPOSIP/252861?mode=full

Lopes, S. C. (2017) Comunidade de prática para o desenvolvimento de competências profissionais voltadas para a resolução de problemas matemáticos de relações contextuais. (289 f.) Tese Doutorado, Educação Matemática, Universidade Anhanguera de São Paulo, São Paulo. https://repositorio.pgsskroton.com.br/handle/123456789/16856

Lesh, R.; Post, T. \& Behr, M. (1988) Proportional reasoning. In: Hiebert, J. \& Behr, M. Number concepts and operations in the middle grades. Tradução de E. E. Ana Isabel Silvestre. (pp.93-118). Lawrence Erlbaum.

Miranda, M. S. (2014) Uma investigação sobre a (re)construção do conhecimento de professores participantes de um grupo que estuda o campo conceitual aditivo. (204 f.) Dissertação Mestrado, Programa de Pós-Graduação em Educação em Educação Matemática]. Universidade Anhanguera de São Paulo, São Paulo. https://repositorio.pgsskroton. com.br/bitstream/123456789/3621/1/Mirtes\%20de\%20Souza\%20Miranda.pdf Miranda, M. S. (2019) Escola como espaço de (re)significação de conhecimentos matemáticos para o ensino: a constituição de um grupo que estuda o currículo e investiga a própria prática. (262 f.) Tese Doutorado, Educação Matemática, Universidade Anhanguera de São Paulo, São Paulo.

Powell, A.; Francisco J. \& Maher, C. (2004) Uma abordagem à Análise de Dados de Vídeo para investigar o desenvolvimento de ideias e raciocínios matemáticos de estudantes. Tradução de Antônio Olimpio Junior. Boletim de Educação Matemática BOLEMA. Rio Claro, 21.

Robutti, O.; Cusi, A.; Clark-Wilson, A., Jaworski B.; Chapman O.; Esteley C.; Goos • M.; Isoda M. \& Joubert M. (2016) ICME international survey on teachers working and learning through collaboration: June 2016 ZDM Mathematics Education 48: 651. https:// doi.org/10.1007/s11858-016-0797-5

Serrazina, M. L. (2012) Conhecimento Matemático para ensinar: papel da planificação e da reflexão na formação de professores. Revista eletrônica de Educação, 6, n. 1, mai. Ensaios. ISSN 1982-7100. http://www.reveduc.ufscar.br/index.php/reveduc/article/ viewFile/355/162.

Zeichner, K. M. (1993) A formação reflexiva de professores: ideias e práticas. EducaProfessores. 